\title{
Grupo Emaús: esteio da Teologia da Libertação no Brasil $(1970-1980)^{1}$
}

\begin{abstract}
Resumo
O Emaús é um coletivo de intelectuais e militantes cristãos formado na década de 1970, com a finalidade de subsidiar movimentos sociais. $\mathrm{Na}$ ocasião, o grupo reuniu alguns dos nomes mais conhecidos da Teologia da Libertação e, desde então, permanece como um dos principais espaços de sociabilidade da chamada esquerda cristã. Com vistas a examinar a formação e a configuração do grupo e acompanhar a atuação de sua primeira geração, dividimos este artigo em três partes. $\mathrm{Na}$ primeira, a título de apresentação, situamos o estudo desse coletivo em nosso programa de pesquisa e expusemos dados relativos à trajetória do Emaús nas décadas de 1970 e 80 . Na segunda, explicitamos algumas das referências teóricas que balizam esta investigação. Por fim, propomos a elaboração de um perfil da geração que fundou e consolidou a presença do Emaús no âmbito da Teologia da Libertação.
\end{abstract}

Palavras-chave: Grupo Emaús. Intelectuais Católicos - História. Teologia da Libertação.

\section{Para citar este artigo:}

FREIRE, Américo. Grupo Emaús: esteio da Teologia da Libertação no Brasil (1970-1980).

Tempo e Argumento, Florianópolis, v. 11, n. 28, p. 212 - 239, set./dez. 2019.

DOI: 10.5965/2175180311282019212

http://dx.doi.org/10.5965/2175180311282019212

\footnotetext{
${ }^{1}$ Esta pesquisa conta com apoio do Conselho Nacional de Desenvolvimento Científico e Tecnológico (CNPq) e da Fundação de Amparo à Pesquisa do Estado do Rio de Janeiro (FAPERJ).
} 


\title{
Emaús Group: mainstay of Liberation Theology in Brazil (1970-1980)
}

\begin{abstract}
The Emaús is a collective of Christian intellectuals and militants formed in the 1970s, in order to provide social movements with means. At the time, the group brought together some of the best-known names in Liberation Theology and, since then, it remains as one of the leading sociability spaces in the so-called Christian left-wing. With a view to examining the group's establishment and setting and following the work of its first generation, we have divided this article into three parts. In the first, by way of presentation, we situate the study of this collective in our research program and expose data related to the Emaús' history in the 1970s and 80s. In the second, we explain some of the theoretical references that ground this research. Finally, we propose the making of a profile for the generation that founded and consolidated the Emaús' presence in the context of Liberation Theology.
\end{abstract}

Keywords: Emaús Group. Catholic Intellectuals History. Liberation Theology.

\section{Apresentação}

“Retorno às bases, às origens".

Eis o mote do discurso proferido por vários intelectuais e segmentos políticos que, nos últimos anos, têm defendido maior inserção das esquerdas no mundo popular. No âmbito de debates que analisam as possíveis razões da perda de substância política dessa corrente política, um dos argumentos aventados é o de que os partidos desse campo, ao se afastarem sobremaneira de seus aliados históricos, teriam transformado-se em máquinas eleitorais a serviço de direções burocráticas, cuja maior preocupação seria a autorreprodução².

\footnotetext{
${ }^{2}$ Ver exemplo desse tipo de abordagem em Reis (2018).
} 
Independentemente da propriedade do diagnóstico, ou de eventuais interesses de posição que estejam informando tal proposição, cabe observar que esse tipo de comentário crítico não representa maiores novidades no campo das esquerdas, o qual, como se sabe, foi formado em estreita conexão com um conjunto de movimentos de trabalhadores então em franca ascensão. No caso brasileiro, não foram poucos os momentos em que as esquerdas se viram aos braços com esses problemas, daí resultando variadas e longas sessões de crítica e autocrítica, tal como transcorreram, por exemplo, em meados da década de 1960, na esteira da derrota política de 1964, ou nas décadas seguintes, como fruto direto do fracasso da luta armada3.

No programa de pesquisa que temos realizado em torno das respostas que as esquerdas procuraram dar a esse e a outros problemas nas décadas de 1970 e 80, concentramos nosso foco, nos últimos anos, no universo da Teologia da Libertação com vistas a estudar o papel exercido por lideranças e correntes cristãs no aggiornamento das esquerdas brasileiras nas décadas em tela e na elaboração e divulgação de um novo discurso político, que teve como pedra de toque o mergulho direto nas bases, no mundo popular.

Para lidar com essas questões, focamos nossa investigação na atuação e nas formulações do Grupo Emaús - um círculo de intelectuais cristãos que assumiu (e assume) papel-chave na configuração da Teologia da Libertação no Brasil nas últimas quatro décadas. Formado na década de 1970 por agentes de pastoral, teólogos, cientistas sociais e líderes e pastores evangélicos, o Emaús se tornou um dos principais eixos de articulação das esquerdas cristãs brasileiras, vindo a desenvolver, como vemos adiante, inúmeras iniciativas no campo da formação pastoral e da educação popular no país.

Coube a 3 frades dominicanos - Frei Betto, Ivo Lesbaupin e Fernando Brito - e a 3 teólogos - Carlos Mesters (carmelita), Leonardo Boff (franciscano) e João Batista Libanio (jesuíta) - a iniciativa de, em meados de 1974, criar um pequeno grupo de trabalho com a finalidade de promover uma agenda de discussões a respeito da possível aproximação teórico-prática do cristianismo com o marxismo. Essas discussões teriam caráter aplicado

\footnotetext{
3 Para análise da trajetória das esquerdas brasileiras ver conjunto de textos em Fortes (2005) e conferir, também, Ferreira e Reis (2007).
} 
e deveriam servir para proporcionar maior substância teórica à atuação dos militantes cristãos no campo social. Para que não houvesse embaraços nem com o regime militar nem com a hierarquia da Igreja, os encontros deveriam ser realizados discretamente, 2 vezes ao ano, no Convento Madre Regina das Irmãs de Santa Catarina, em Petrópolis. Para o público externo, as reuniões do grupo tinham como finalidade estabelecer parâmetros à prática da catequese católica. (BETTO, 2012; LESBAUPIN, 2013; OLIVEIRA, 2014, informação oral).

O chamado "Grupo de Petrópolis", nos anos seguintes, fixou e consolidou regras e procedimentos. As reuniões se tornaram semestrais, cobriam um fim de semana, como nos retiros religiosos, e seguiam a mesma agenda. Em um primeiro momento, apelidado de Cosa Nostra, abria-se um espaço de tempo para a livre troca de impressões e de experiências pessoais. O segundo era reservado à análise da conjuntura política e eclesial, logo seguido por uma tomada de posições do coletivo sobre determinada questão. Por fim, realizava-se uma celebração de cunho ecumênico. (BINGEMER, 2014, informação oral).

Nada deveria ser registrado, conforme a regra de ouro de segurança que dava fundamento à existência do grupo, e os nomes de novos membros deveriam ser apreciados e aprovados pelo coletivo. O grupo agregou novos nomes ao longo da década de 1970 e no início da década seguinte, dentre eles: a) teólogos católicos vinculados à Teologia da Libertação; b) agentes de pastoral que desenvolviam trabalhos junto a movimentos sociais e às comunidades eclesiais de base (CEBs); c) cientistas sociais originários da Ação Católica Brasileira (ACB); e d) lideranças históricas do campo protestante, perfazendo um total de 15 a 20 pessoas (OLIVEIRA, 2018).

No final da década de 1980 e no início da década seguinte, o grupo enfrentou grave crise na esteira do colapso do socialismo soviético. Nas palavras de um de seus membros mais ativos, o sociólogo Pedro Ribeiro de Oliveira: 
O Muro de Berlin caiu em cima da gente. Caiu em cima do "Comitê Central". As reuniões se esvaziaram e chegamos mesmo a pensar em acabar com o grupo. Só que, em 1994, quando estávamos comemorando os 50 anos de aniversário do Marcelo Barros, resolvermos dar continuidade ao grupo, só que com outro espírito. Na retomada, acabamos com essa ideia de "comitê central", com a proposta de nos reunirmos para tomar decisões e levarmos juntos uma mesma bandeira. Desde então, a gente se reúne fraternalmente para definir qual deve ser a linha do grupo para os temas em pauta. (OLIVEIRA, 2014, informação oral).

Foi por ocasião dessa retomada que o grupo passou a ser denominado "Emaús", em alusão ao episódio evangélico no qual Jesus ressuscitado, a caminho do povoado chamado Emaús, encontra dois discípulos abatidos por ele ter sido crucificado sem que suas promessas se cumprissem. Sem se dar conta de que estão acompanhados pelo próprio Jesus, ouvem o que ele diz, enfim abrem os olhos da fé e, no jantar em Emaús, reconhecem, ao partilharem o pão, a presença viva daquele que fora crucificado (A BÍBLIA, 1964).

Na década de 2010, o Emaús tem assumido um novo perfil: está mais numeroso e menos preocupado em manter reserva sobre sua agenda de reuniões, realizações e demandas. Um exemplo nesse sentido se deu em novembro de 2014, quando uma delegação do grupo, liderada por Frei Betto e Leonardo Boff, foi recebida em audiência pela presidente Dilma Rousseff. Na oportunidade foi divulgada à imprensa a carta "O Brasil que queremos", contendo as principais reivindicações do grupo. Nela estão presentes temas como: a) a defesa da reforma política; b) a adoção de uma política econômica inclusiva; c) a defesa dos direitos dos povos indígenas e quilombolas; d) a democratização dos meios de comunicação; e) a universalização os direitos humanos; e f) a defesa da ética na política e da política (BETTO, 2014a).

Outro indício nesse mesmo sentido é a presença do nome do grupo em vários verbetes no Dictionnaire historique de la Théologie de la Libération - importante obra de referência publicada na Bélgica e na França, sob a direção de professores belgas (CHEZA; ZAAVEDRA; SAUVAGE, 2017). Também digno de nota, no entanto, é o fato de não existir no livro um verbete específico sobre o grupo.

Duas têm sido as frentes de pesquisa com vistas a levantar fontes sobre nosso objeto de pesquisa. Uma delas é a consulta em obras de autoria de membros do grupo 
que apresentam dados e análises sobre a formação e a trajetória do Emaús ${ }^{4}$. Outra frente, a principal e mais fértil, é a voltada a recolher depoimentos orais de membros do grupo 5 . Até o momento foram ouvidos 17 deles (11 homens e 6 mulheres) ${ }^{6}$.

Tendo por base esse breve apanhado da trajetória do grupo, passemos a apresentar alguns resultados da pesquisa ora em curso. Dividimos nossa exposição em duas seções.

A primeira, de cunho mais especulativo, explicita algumas das referências que têm balizado a investigação. A proposta consiste em desenvolver reflexões e levantar hipóteses em torno da modalidade de organização expressa em Emaús e sobre o caráter próprio do trabalho dos membros do grupo no contexto da Teologia da Libertação e do “Cristianismo da Libertação”, conforme os termos propostos por LOWY (2007).7.

A segunda seção, de cunho mais descritivo, trata de aspectos da formação e da composição do grupo entre as décadas de 1970 e 80. O objetivo, aqui, é acompanhar o percurso da geração que lançou, deu forma e consolidou a presença do grupo no âmbito da Teologia da Libertação no país. Pretende-se, como horizonte de pesquisa, avançar na investigação sobre outras fases da história do Emaús. O mesmo a dizer quanto ao projeto de elaborar uma biografia coletiva - uma prosopografia - dos membros do Emaús.

\footnotetext{
${ }^{4}$ No âmbito da produção memorial de membros do Emaús, ou sobre eles, cabe destacar os livros de Oliveira (2018), Souza (2015). e Cechin (2017).

${ }^{5}$ Concentramos nossa atenção, neste artigo, nos depoimentos da (e sobre a) primeira geração do Emaús. E mais: fizemos o uso restrito desses depoimentos com vistas a mapear a trajetória e a composição primária do grupo. Mais tarde, no âmbito da investigação, prevê-se a análise em pormenor das memórias produzidas por essa geração sobre temas como a presença feminina no Emaús, os conflitos internos, a relação entre as diferentes denominações religiosas presentes no grupo e a crise de meados da década de 1980 mencionada.

6 Foram entrevistados os seguintes membros de Emaús: Edson Fernando, Rio de Janeiro, 2017; Faustino Teixeira, Juiz de Fora, 2018; Frei Betto, Rio de Janeiro, 2012; Ivo Lesbaupin, Rio de Janeiro, 2013; Leonardo Boff , Petrópolis, 2013; José Oscar Beozzo, São Paulo, 2018; Lucia Ribeiro, Rio de Janeiro, 2014; Luiz Alberto Gómez de Souza, Rio de Janeiro, 2014; Luiz Eduardo Wanderley, São Paulo, 2018; Marcia Miranda, Petrópolis, 2013; Marcelo Barros, Havana (Cuba), 2013; Maria Clara Bingemer, Rio de Janeiro, 2014; Maria Helena Arrochellas, Petrópolis, 2018; Maria José Rosado Nunes, São Paulo, 2017; Pedro Ribeiro de Oliveira, Juiz de Fora, 2014. Tereza Cavalcanti, Rio de Janeiro, 2014. Zwinglio Dias, email, 2018.

7 Por "cristianismo da libertação" Löwy (2007) compreende o amplo processo de mudança que atingiu setores da Igreja Católica latino-americana na esteira do Concílio Vaticano II, no sentido de firmar uma Igreja popular e voltada à libertação. Nesse processo, que no Brasil foi bastante impulsionado pelo trabalho de formação das CEBs, ganhou fôlego um conjunto orgânico de diretrizes e práticas que passou a ser denominado Teologia da Libertação.
} 


\section{Emaús como formação independente}

Frei Betto, em entrevista concedida ao autor, chamou atenção para a importância de manter em segredo as reuniões do grupo. Ao ser inquirido acerca das razões dessa reserva, o frade dominicano assim respondeu:

Nossa preocupação maior, naquele momento, não era tanto com o regime militar, mas sim com uma possível intervenção por parte da hierarquia da Igreja Católica quanto a criar obstáculos ou mesmo barrar a realização das nossas reuniões. (BETTO, 2012 informação oral)

O Emaús, como vimos, foi criado como uma articulação de intelectuais e militantes cristãos com o propósito de debater questões relativas à religião e à política, tendo em vista subsidiar e alimentar movimentos sociais. Para isso, era mister constituir um espaço de debate livre e fora da órbita das estruturas eclesiásticas, tal como registrou Frei Betto. (BETTO, 2012, informação oral). E mais: deveria ser um fórum que congregasse leigos e religiosos cristãos de várias denominações em torno do mesmo propósito libertador. As reuniões tiveram início em 1974 e, desde então, permanecem fundadas nos mesmos valores e perseguem os mesmos objetivos.

Dito isso, tratemos de levantar algumas hipóteses de trabalho sobre a primeira etapa da longeva experiência do Emaús. Um aspecto interessante no formato que veio a ser adotado no grupo diz respeito ao seu caráter horizontal e não institucionalizado, ou seja, não há corpo diretivo a conduzir o grupo e a tendência predominante entre seus membros foi - e continua a ser - mantê-lo como uma articulação livre e não como uma entidade. Vejamos isso melhor.

O Emaús, como referido, surgiu da ação exclusiva de religiosos interessados em construir e vivenciar uma Igreja menos hierárquica e mais popular e democrática. Portanto, não fazia sentido reproduzir, no âmbito do grupo, estruturas hierárquicas de saber e poder. Os teólogos-doutores sentavam e debatiam, de igual para igual, com os frades dominicanos, dois deles - Betto e Ivo - ainda em formação. Essa postura mais igualitária, coerente com o espírito fundador do Emaús, persistiu nos anos seguintes, ainda que, diante da expansão numérica do grupo, mostrou-se necessário indicar a presença de um coordenador para levar adiante as discussões. João Batista Libanio, por muito tempo, cumpriu esse papel. 
Cremos que um dos pontos-chave da configuração do Emaús foi a decisão do grupo de mantê-lo como uma articulação de indivíduos que, de forma livre e voluntária, passou a se reunir em torno de um projeto de trabalho comum. Há no Emaús, como visto, organização, previsão, regularidade e regras previamente definidas para que as reuniões do grupo sejam realizadas a contento. E nada mais. Ou seja, a formação do grupo não pressupôs o compromisso com a criação de uma entidade ou de uma instituição dirigida ao trabalho popular, tal como era prática comum naquela quadra fértil da vida política brasileira $^{8}$. Vários membros do Emaús, por sinal, atuaram diretamente em entidades dessa natureza, ao mesmo tempo que contribuíram para a formação de redes nacionais e latino-americanas que compuseram a constelação que deu suporte e disseminou os princípios orientadores da Teologia da Libertação. Portanto, o Emaús, por opção, permaneceu na retaguarda, como esteio e elemento impulsionador na formulação de projetos e na criação de entidades de formação de quadros, como o Centro Ecumênico de Serviços à Evangelização e Educação Popular (CESEEP) ${ }^{9}$ e o Centro de Estudos Bíblicos $(\mathrm{CEBI})^{10}$.

Caso tudo isso faça sentido, cabe inquirir, então, a respeito da modalidade de associação expressa no Emaús.

Afinal:

- Do que se trata?

- Como é possível caracterizar essa articulação:

- Como um círculo de intelectuais?

- Como uma fraternidade cristã?

- Como um grupo de ação estratégica?

- E quanto à natureza do trabalho proposto e realizado pelos membros do Emaús:

○ Como qualificá-lo?

\footnotetext{
${ }^{8}$ Faltam estudos de conjunto sobre o trabalho desses coletivos e entidades voltados ao trabalho popular. Quanto à formação política no meio sindical, ver Manfredi (1996); sobre o campo da educação popular, ver Marques (2008).

9 O CESEEP foi fundado em 1982, por um grupo de padres, pastores, biblistas e cientistas sociais. Trata-se de um centro ecumênico de educação popular voltado a dar apoio a movimentos e lideranças populares. Sobre a entidade, ver verbete em Cheza, Zaavedra e Sauvage (2017, p. 491).

${ }^{10} \mathrm{O}$ CEBI foi fundado em 1979 e tem como projeto aprofundar e divulgar a leitura popular da Bíblia. A respeito da entidade, ver verbete em Cheza, Zaavedra e Sauvage (2017, p. 492).
} 
Dois autores, em particular, têm ajudado a pensar sobre esses problemas: a) o sociólogo britânico Raymond Williams; e b) o historiador francês Jean-François Sirinelli. Vejamos.

Williams (1992), em Cultura, ao propor as bases de uma nova sociologia da cultura, registra a importância de pensar em novos instrumentos de análise com vistas a estudar pequenos grupos que assumiram - e assumem - papel relevante na cultura inglesa dos últimos séculos. Para lidar com esse fenômeno, propôs a noção de formação cultural independente, na qual busca englobar os grupos que se formam de maneira voluntária, fora do raio de ação das instituições culturais, e estruturam-se tendo por base valores e princípios comuns.

O sociólogo britânico, em Cultura e materialismo (WILLIAMS, 1999), dedica especial atenção ao estudo de uma dessas formações independentes - o Círculo de Bloomsbury, um grupo formado por intelectuais e artistas de renome e que veio a exercer ampla influência na cultura inglesa na primeira metade do século passado. Fizeram parte de Bloomsbury nomes como John Maynard Keynes (economista), Virginia Woolf (escritora), Duncan Grant (pintor), Lytton Strachey (biógrafo) e Leonard Woolf (ensaísta), entre outros. Segundo Williams (2011, p. 224), Bloomsbury carregava os valores clássicos do Iluminismo burguês:

O grupo era contra o convencionalismo, a superstição, a hipocrisia, a pretensão e o espetáculo público. Era também contra a ignorância, a pobreza, a discriminação social e racial, o militarismo e o imperialismo. [...] Contra todos esses males, eles apelavam não a uma ideia alternativa da sociedade como um todo. Ao contrário, apelavam ao valor supremo do indivíduo civilizado, cuja pluralização, com mais e mais indivíduos civilizados, era a única direção social aceitável.

Para melhor apreender o significado do grupo, Williams (1999) propõe uma abordagem que leva em conta duas variáveis analíticas. A primeira delas consiste em examinar os valores e princípios que cimentam Bloomsbury como uma "associação de amigos" autoproclamada. No caso, o foco recai sobre os termos e as proposições dos membros do grupo. A segunda abre o campo de análise com vistas a situar o grupo em estruturas sociais mais amplas. Heloísa Pontes (1998), autora de livro inspirado 
diretamente nas proposições de Raymond Williams, assim resume o partido metodológico do autor nesse caso:

O ponto central e decisivo da análise, para Raymond Williams, reside em ver o significado de Bloomsbury Group - e de todo e qualquer agrupamento desse tipo - para além da autodefinição de seus membros. Sendo inegavelmente um "grupo de amigos", ele é também e a um só tempo um grupo cultural e social. Apreendê-lo enquanto tal exige $o$ entrelaçamento de uma dupla perspectiva. De um lado, o resgate dos termos com que seus integrantes se viam e queriam ser apresentados e, de outro, a análise desses termos a partir de seus significados sociais e culturais mais gerais. [...] Do ponto de vista analítico, o que importa, para Williams, são as relações concretas do grupo com a totalidade do sistema social, e não apenas significados sociais e culturais mais gerais (PONTES, 1998, p. 15).

Diante do exposto, tratemos de retomar o fio da meada, agora à luz das proposições de Raymond Williams. Quanto à natureza associativa do Emaús, cremos que se mostra fértil para a pesquisa classificarmos o grupo como uma formação associativa independente, seja por suas origens, seu modus operandi ou seu caráter marcadamente autônomo das instituições religiosas que provêm quadros para o grupo. Por certo, é mister melhor qualificar essa autonomia em momentos posteriores da pesquisa, dado que o Emaús, ao lado de atuar em faixa própria, sempre manteve relações próximas com alas progressistas da Igreja Católica de outras denominações cristãs, alimentando e ajudando a compor o largo campo da Teologia da Libertação.

O partido metodológico de Raymond Williams, esquematicamente exposto, sugere, ainda, abordagens em que se busque articular o estudo da dinâmica interna do grupo e da forma pela qual narrativas autorreferidas são construídas, ao lado de pensá-lo em uma perspectiva mais larga nos planos social, religioso e político.

Jean-François Sirinelli, nome referência da historiografia dos intelectuais de cariz francês, advém de tradição diferente da de Raymond Williams e sua obra, como veremos, comporta outros problemas. Enquanto as preocupações de Williams giraram em torno de construir instrumentos de análise que fixassem as bases de uma sociologia da cultura que englobasse diferentes abordagens e métodos sob clara inspiração marxista - daí o enfoque voltado à totalidade social -, Sirinelli teve e tem dirigido suas pesquisas em torno 
do clássico tema, na cultura e na história francesas, das relações entre intelectuais e espaço público, daí erigindo o que François Dosse (2007, p. 44) denomina uma "história política dos intelectuais".

Sirinelli é um dos autores que mais têm influenciado a historiografia brasileira sobre temas relativos à história social dos intelectuais, isso porque seus trabalhos, de cunho metodológico e temático, têm produzido noções que se mostram operacionais para os que, no campo da história cultural ou da história política, buscam examinar mais detidamente o ambiente próprio dos intelectuais, seus percursos e suas formas de convivência. De seu repertório, as noções de itinerário (como uma trajetória não linear) e as estruturas de sociabilidade (como espaços próprios de proximidade entre os intelectuais) e de geração (identificada por um marco fundador) têm servido de roteiro de pesquisa para inúmeros trabalhos (SIRINELLI, 1986, 1996).

Esse aparato analítico de Sirinelli $(1986,1996)$ tem nos subsidiado, tendo em vista explorar alguns temas centrais da pesquisa sobre o grupo em tela, entre os quais o que busca compreender as regras e o modo de convivência que conformaram a sociabilidade no Emaús. Em nosso modo de entender, estudar esse "microclima”, nos termos propostos pelo autor ${ }^{11}$, leva-nos a considerar, entre outros, dois aspectos marcantes da formação e do modus operandi do grupo aludido: a condição de semiclandestinidade que marcou por um largo tempo a trajetória do Emaús e o caráter rotineiro e ritualístico de suas reuniões semestrais.

Mencionamos a maneira pela qual o grupo organiza seus encontros semestrais. Há espaço e tempo para trocas pessoais, análises de conjuntura e a hora final da celebração, realizada significativamente aos domingos. Sobre esse modelo de reuniões, um aspecto a ser explorado na investigação é pensá-lo em linha de continuidade com os princípios e as práticas que referenciavam os encontros que, nas décadas de 1950 e 1960, eram realizados no âmbito da $A C B$, em particular em suas seções especializadas, como a Juventude Operária Católica (JOC), a Juventude Estudantil Católica (JEC) e a Juventude

\footnotetext{
1 Sobre a noção de "microclima", ver Sirinelli (1996, p. 253); ver, também, Trebitsch (1992, p. 13) e Gomes (1999, p. 18-31). Para importante mapeamento sobre o tema da sociabilidade intelectual na historiografia, ver Gontijo (2005).
} 
Universitária Católica (JUC) 12. Nesses movimentos se adotava o método "Ver, Ouvir e Agir”, o qual foi assim caracterizado pelo papa JOÃO XXIII (1961) na encíclica Mater et Magistra:

Primeiro, o "estudo da situação" concreta; segundo, a "apreciação da mesma à luz desses princípios e diretrizes"; terceiro, o "exame e determinação do que se pode e deve fazer para aplicar os princípios e as diretrizes à prática, segundo o modo e no grau que a situação permite ou reclama". São os três momentos que habitualmente se exprimem com as palavras seguintes: “ver, julgar e agir"”3.

O Emaús, como pudemos verificar, foi formado como um coletivo de reflexão/ação. Trata-se de um grupo cuja marca foi produzir e aplicar saberes e práticas. Nas décadas em tela, sobressaiu seu caráter mais prático e menos especulativo, voltandose mais diretamente à criação de instrumentos de intervenção nos campos religioso e social. Não por acaso, vários de seus fundadores tiveram origem e militaram em movimentos da ACB, como Frei Betto, Frei Ivo, Luiz Alberto Gomez de Souza, Pedro Ribeiro de Oliveira, entre outros.

A celebração ecumênica é outro momento-chave para melhor compreender as bases constitutivas do "Grupo de Petrópolis", depois Emaús. A missa dominical assume novas feições e nela se rompe com regras hierárquicas. O celebrante que compartilha 0 pão e o vinho é o sacerdote e/ou o leigo; o homem e/ou a mulher; o católico e/ou o pastor. O espírito é de comunhão e de irmandade, como se pode verificar no seguinte relato de Pedro Ribeiro de Oliveira:

Tenho lembrança de uma celebração muito bonita realizada no domingo de manhã no alto do morro nas proximidades do Colégio Madre Regina. $O$ padre Orestes Stragliotto nos fez orar o Ato dos Apóstolos: "estamos aqui por ordem de Deus. Não há bispos. Ninguém nos convocou. Deus nos chamou e aqui vamos rezar". Então fazíamos a nossa celebração e, na consagração, na missa, Leonardo Boff propôs que eu conduzisse o ritual. Eu fiquei sem graça, nunca fui seminarista, não sabia nada, mas fiz, todo mundo ajudando. [...] Então, esse era o espírito do grupo, é o espírito do grupo; era um grupinho que que estava recuperando a velha mística de JEC de que iriámos fazer a revolução, mudar esse mundo. Deus está com a gente, nós vamos fazer alguma coisa. (OLIVEIRA, 2014, informação oral)

\footnotetext{
${ }^{12}$ A Ação Católica, no Brasil, foi criada em 1935 e teve como principal objetivo estreitar os vínculos da instituição com os leigos.

${ }^{13}$ Cf. IHU (2011).
} 
O Emaús, portanto, estabelece-se nas décadas em tela como um coletivo que transita em faixa própria no seio do universo cristão. Assentado em princípios como autonomia e horizontalidade, o grupo reuniu figuras-chave da Teologia da Libertação que se mostraram interessados em vivenciar sua fé - e seu compromisso político - tendo em vista a leitura que faziam do Cristianismo como uma mensagem transformadora. Um aspecto interessante aqui, entre outros, é que essa vivência se dá não em oposição, mas em conformidade com o trabalho que realizam no interior de suas denominações religiosas. Como vemos a seguir, poucos foram os que se afastaram em definitivo de suas igrejas, seja por moto próprio, seja por pressão da instituição.

\section{Núcleos formadores e perfil preliminar}

Passemos agora a nos fixar na formação e na composição do Emaús. No decorrer da pesquisa, temos dividido a história do grupo entre as décadas de 1970 e 1980 em dois momentos. O primeiro deles cobre o período da fundação, em 1974, até a criação do CESEEP, em 1982. O segundo se estende pela década de 1980, até a referida mudança na denominação do grupo para Emaús.

Cinco foram as vertentes que ajudaram a compor o grupo no primeiro momento aludido: a) dos militantes dominicanos; b) dos teólogos católicos formados no exterior sob a égide do Concílio Vaticano II; c) de cientistas sociais marcados pelo trabalho na ACB; d) de religiosos católicos (sacerdotes e agentes de pastoral) diretamente voltados ao trabalho popular; e, finalmente, e) composta por pastores e líderes protestantes.

O termo vertente é utilizado na pesquisa para fins de referência e diz respeito aos núcleos que originaram o grupo e que têm identidade, história e experiências próprias. Pela natureza horizontal e orgânica da articulação, acima referida, não há porque aqui privilegiarmos o estudo do jogo concorrencial entre elas, até porque, como se vê adiante, sempre houve trânsito e intercâmbio entre os núcleos, fazendo com que, a depender do tema, eles se reconfigurassem ou mesmo se dispersassem. Cada membro do grupo, cabe observar, estava - e está - ali respondendo por si e não como representante de ordens, denominações religiosas ou entidades de qualquer natureza. O interessante na história 
do Emaús, além de sua diversidade, é exatamente verificar como se deu a mescla dessas diferentes vertentes e como todo esse processo contribuiu para alimentar a Teologia da Libertação no país.

Independentemente de tudo isso, cremos que parece válido pensar acerca da contribuição de cada um desses núcleos para a configuração e para o trabalho desenvolvido no grupo nessa fase de implantação. Tratemos de ensaiar algumas hipóteses.

Por certo, não há como esquecer a marca de origem dominicana do grupo, haja vista a iniciativa ter saído da cabeça de 3 frades da Ordem dos Pregadores. Claro deve estar, porém, que eles não estavam a mando ou a serviço da Ordem. Fizeram de moto próprio e com base na ideia de que o trabalho do grupo se coadunava com o carisma dominicano, o qual, segundo Frei Betto, firma-se em 3 pilares:

1) lutar por justiça e por uma sociedade de partilha dos bens da Terra e dos frutos do trabalho humano (pobreza); 2) fidelidade ao carisma de São Domingos (obediência); 3) gratuidade na entrega amorosa e solidária de nossas vidas a todos, e em especial aos que carecem de condições dignas de vida (castidade) (BETTO, 2016).

Qualquer análise sobre o grupo também deve levar em conta tanto a devoção dominicana desses 3 frades quanto sua experiência pessoal de antes e de depois de 1974 . Betto, Ivo e Fernando estiveram entre os religiosos que foram presos durante o regime militar brasileiro, sob a acusação de envolvimento na resistência armada contra ele. Foram processados, julgados e condenados a cumprir 4 anos de pena em cárceres no Estado de São Paulo. Foram, enfim, libertados em outubro de 1973.

Nos tempos de cárcere, os 3 participaram de greves de fome em protesto contra decisões de autoridades prisionais; mantiveram-se atentos aos novos rumos da Igreja latino-americana sob a inspiração de Medellín; debateram com outros presos políticos sobre os rumos da resistência ao regime e ao capitalismo; atuaram na formação de presos comuns; além de trocarem numerosa correspondência com seus confrades e vários outros religiosos, na qual costumavam se referir à experiência prisional como tempos de provação, sacrifício e aprendizado. Saíram do cárcere convictos da necessidade da Igreja 
se voltar a uma ação efetiva no campo popular, o que pressupunha a atuação do sacerdote junto ao povo, convivendo com ele e como ele. Dando consequência a esse postulado, os 3 mergulharam em uma práxis evangélica na qual o pobre é sujeito e protagonista das transformações históricas. Cada qual assumiu esse compromisso de um jeito, com uma assinatura própria. Ao mesmo tempo, estiveram juntos em várias ocasiões e projetos comuns ${ }^{14}$.

Frei Fernando, o mais velho dos 3, às vésperas de completar 37 anos, partiu para a Diocese de Goiás com vistas a trabalhar ao lado de Dom Tomás Balduino junto às CEBs. Mais tarde, nos anos 1990, transferiu-se para Sítio do Conde, no interior do Estado da Bahia, para atuar como missionário e viver junto ao povo da região. Em 2002, reuniu seus escritos no livro Cartas do sítio. (BRITO, 2002).

Ivo, o mais novo, então com 27 anos, optou por finalizar seus estudos teológicos no Instituto Teológico de Petrópolis, quando teve a oportunidade de travar contato com o teólogo e professor Leonardo Boff. Paralelamente, desenvolveu trabalho pastoral junto às CEBs de Nova Iguaçu. Em 1977, deixou a Ordem Dominicana para seguir carreira acadêmica. Fez doutorado em Sociologia na Université de Toulouse Le-Mirail, na França, e, de volta ao Brasil, tornou-se professor na Escola de Serviço Social da Universidade Federal do Rio de Janeiro (UFRJ), ao mesmo tempo que veio a desenvolver e coordenar projetos de assessoria no Instituto Superior de Estudos da Religião (ISER).

Frei Betto, aos 29 anos, partiu de armas e bagagem para Vitória, capital do Estado do Espírito Santo. Ali, fora do alcance direto das autoridades policiais, pôde reunir boas condições para se inserir, direta e pessoalmente, no mundo popular. Para isso, pôde contar com o apoio de Dom João Batista da Mota e Albuquerque e Dom Luis Fernandes respectivamente arcebispo e bispo auxiliar de Vitória -, dois nomes da vasta galeria de figuras da Igreja Católica que se mostraram decisivos em sua formação e seu trabalho como militante cristão.

Em paralelo, os 3 tomaram a iniciativa de levar adiante a proposta de criar um grupo que deveria alimentar e referenciar o trabalho pastoral e evangélico no mundo

\footnotetext{
${ }^{14}$ Sobre a trajetória dos frades dominicanos na prisão, ver Betto (2006).
} 
popular. Betto e Ivo são presenças constantes nas reuniões do Emaús até os dias de hoje. Já Fernando, morando distante do Rio de Janeiro e com problemas de saúde, não tem mais participado das sessões semestrais do grupo. Os 3 deram - e dão - ao Emaús testemunho militante de confiança no protagonismo popular, tendo em vista a construção de um reino de justiça.

Carlos Mesters, João Batista Libanio e Leonardo Boff compuseram o grupo de teólogos que fundou o "grupo de Petrópolis". Mesters, na ocasião, era o mais velho e o único estrangeiro do grupo. Nascido na Holanda, em 1931, chegou ao Brasil como missionário em fins da década de 1940. Já como membro da Ordem Carmelita, fez seus estudos superiores no exterior, tornando-se biblista e doutor em Teologia, com formação pelos institutos bíblicos de Roma e de Jerusalém. De retorno ao Brasil, associou a atividade de professor das Sagradas Escrituras em instituições de Ensino Superior religiosas ao trabalho pastoral contínuo junto às CEBs, quando formulou um método próprio de leitura popular da Bíblia ${ }^{15}$. No âmbito das discussões no Emaús, Mesters recolheu ideias e parceiros para colocar de pé, em 1979, o CEBI, ladeado por Jether Ramalho, Lucília Ramalho, Agostinha Vieira de Mello, Orestes Stragliotto e Frei Betto, entre outros.

João Batista Libanio nasceu em 1932 e faleceu em 2014. Jesuíta, teve sólida formação teológica na Alemanha e na Itália. No Brasil, cumpriu longa e reconhecida carreira acadêmica como professor e como autor de ampla obra sobre temas teológicos. Foi discípulo do teólogo jesuíta alemão Karl Rahner e parceiro intelectual do filósofo jesuíta brasileiro Henrique de Lima Vaz - figura central na formulação de conceitos que fundamentaram a atuação Ação Popular (AP) no Brasil. No Grupo Emaús, Libanio teve papel fundamental como organizador de pautas e como referência intelectual e pessoal ${ }^{16}$.

Leonardo Boff é o mais conhecido teólogo da libertação no Brasil. Nascido em 1939, ingressou na Ordem dos Franciscanos 20 anos depois, vindo a realizar seus estudos

\footnotetext{
15 Sobre a trajetória e o método de Carlos Mesters, ver Cavalcanti (2007); ver, ainda, o verbete de Fidèle Mabundu sobre Mesters em Cheza, Zaavedra e Sauvage (2017, p. 318-320).

16 Sobre a trajetória de João Batista Libanio, conferir verbete de Pedro Rubens Ferreira em Cheza, Zaavedra e Sauvage (2017, p. 277-279). A respeito do papel de Libanio como coordenador do Emaús, ver Betto (2014b).
} 
de doutoramento em Teologia em Munique, na Alemanha, sob a supervisão de Karl Rahner. Foi professor em instituições religiosas franciscanas e na Universidade do Estado do Rio de Janeiro (UERJ); exerceu enorme influência em algumas das mais importantes publicações religiosas do país, tais como a Revista Eclesiástica Brasileira (ESB) e a edição brasileira da Concilium, além de ser autor de vasta obra teológica. Os conflitos frequentes e abertos com o Vaticano, em particular com a direção da Congregação pela Doutrina e pela Fé, fizeram-no sair da Igreja em $1994^{17}$. É um intelectual público com ampla presença nos meios políticos, jornalísticos e culturais. A respeito do convite para participar do Emaús, Boff assim registrou em entrevista:

Eles [os frades dominicanos] tramaram tudo na prisão; nos armaram uma cilada. Foi uma coisa deliberada. Achavam que teólogos como eu, meu irmão, Clodovis, Libanio e outros, que tínhamos acabado de chegar da Europa, não estávamos suficientemente preparados nos estudos de marxismo para produzir uma crítica social consequente. Tinham que mudar nossa cabeça. Daí a proposta de debatermos a fundo sobre o instrumental de análise que melhor compreende o funcionamento da sociedade capitalista e sobre a responsabilidade da teologia nisso. Foi aí que tudo começou e esse movimento algo clandestino já dura mais de 40 anos. (BOFF, 2013, informação oral).

José Oscar Beozzo e Clodovis Boff compuseram a segunda leva dos teólogos. Oscar Beozzo nasceu em 1944 e é padre diocesano em Lins, interior do Estado de São Paulo. É licenciado em Sociologia pela Universidade Católica de Louvain e doutor em História pela Universidade de São Paulo (USP). É figura de proa na Comissão para o Estudo da Igreja na América Latina (CEHILA), também tendo atuado como reitor do Instituto Teológico de Lins (ITEL) e como professor de História na Faculdade de Teologia Nossa Senhora de Assunção e no Instituto Teológico de São Paulo. Ingressou bem cedo no Grupo de Petrópolis e permanece como uma de suas principais referências. Coube a ele o desafio de colocar de pé o CESEEP, contando com o suporte da Arquidiocese de São Paulo, então sob o comando de Dom Evaristo Arns, bem como de Frei Gorgulho, Jether Ramalho, Júlio de Santa Ana e Luiz Eduardo Wanderley. O CESEEP, em seus 36 anos de

\footnotetext{
${ }^{17}$ A respeito da trajetória de Leonardo Boff, ver verbete de Juan Navarrete em Cheza, Zaavedra e Sauvage (2017, p. 86-88).
} 
existência, destaca-se como importante centro formação de lideranças religiosas no país sob a égide da Teologia da Libertação.

Clodovis Boff nasceu em 1944 e é membro da Ordem dos Servos de Maria. Formou-se e doutorou-se em Teologia pela Universidade Católica de Louvain. Clodovis, em meados da década de 1970, já era visto como um dos principais nomes da Teologia da Libertação no Brasil, dada a excelente recepção de sua tese de doutorado em que propôs construir modelos analíticos com vistas a fundar uma epistemologia e uma metodologia próprias para essa corrente teológica. Foi nessa ocasião que ingressou no Grupo de Petrópolis e passou a dar aulas em instituições como o Instituto Teológico de Petrópolis e a Pontifícia Universidade Católica do Rio de Janeiro (PUC-Rio). Recentemente, já no século XXI, rompeu com os fundamentos da Teologia da Libertação, por considerá-la parcial e comprometida quando coloca o pobre - e não Cristo - como princípio operativo da teologia. Clodovis, antes desse rompimento, colocou em pauta questões importantes para o Grupo Emaús, entre as quais a necessidade de maior reflexão sobre a presença dos cristãos na vida política. Voltamos a esse ponto na seção seguinte ${ }^{18}$.

No âmbito das discussões do grupo, seus primeiros membros viram a necessidade de contar com a presença de cientistas sociais. Daí o convite a Pedro Ribeiro de Oliveira, o qual passou a compor a articulação em 1975. Logo depois, Luiz Eduardo Wanderley e Luiz Alberto Gomez de Souza, ambos sociólogos, também passaram a fazer parte do grupo.

Os três são leigos católicos, tiveram ligações com a ACB, realizaram estudos de formação no exterior e mantêm forte compromisso com o Emaús até hoje. Ribeiro de Oliveira é o mais novo deles. Nasceu em 1945, militou na juventude católica e formou-se doutor em Sociologia na Universidade Católica de Louvain. Exerceu a docência superior em várias universidades no Estado de Minas Gerais e mantém vínculos com o ISER. Destaca-se como um dos melhores memorialistas do grupo e compõe a linha de frente do movimento Fé e Política, mais um dos desdobramentos do Emaús.

Luiz Eduardo Wanderley é figura de amplo prestígio acadêmico em São Paulo. Fez seu doutoramento em Ciência Sociais na USP e seu pós-doutoramento na École des

\footnotetext{
18 Sobre a trajetória de José Oscar Beozzo e de Clodovis Boff, ver verbetes de Pierre Sauvage e Agenor Brighenti em Cheza, Zaavedra e Sauvage (2017, p. 79-80 e 84-86).
} 
Hautes Études em Sciences Sociales, em Paris. É professor titular da Pontifícia Universidade Católica de São Paulo (PUC-SP), instituição que chegou a dirigir como reitor na década de 1980. No final dos anos 1950 e na década de 1960, teve ampla atuação na ACB e em movimentos voltados à educação popular. Na universidade, destacou-se como um teórico dedicado a estudar o vasto campo dos movimentos sociais e da educação popular. Contribui continuamente com os debates do Emaús, tendo cumprido papelchave na montagem e na manutenção do CESEEP.

Luiz Alberto Gomez de Souza é outro membro do Emaús com vinculações históricas com a ACB, no caso com a JEC. Nascido em 1935, teve intensa participação política nos anos que antecederam o golpe civil-militar de 1964. Trabalhou como cientista social em vários países, como Chile, México, França e Itália, vindo a doutorar-se em Ciências Sociais pela Universidade Sorbonne em 1979. Em suas idas e vindas ao país, terminou por se vincular ao Emaús em 1977. Atuou como professor em várias instituições e, hoje em dia, exerce a coordenação do Programa de Estudos Avançados em Ciência e Religião na Universidade Cândido Mendes (UCAM) ${ }^{19}$.

O grupo de Petrópolis, também nessa primeira fase, incorporou Antonio Cechin e Orestes Stragliotto. Trata-se do núcleo gaúcho do Emaús, uma vez que ambos nasceram e trabalharam no Rio Grande do Sul. Cechin nasceu em 1927 e Stragliotto no ano seguinte. Tinham por volta de 50 anos quando ingressaram no grupo. Cechin foi irmão marista, professor, doutor em Teologia pela Universidade Gregoriana de Roma, animador de CEBs e figura-referência de um amplo leque de movimentos sociais gaúchos, entre os quais o Movimento dos Sem-Terra (MST). Teve também forte presença no campo da educação popular. Faleceu em $2016^{20}$. Stragliotto foi membro da Congregação dos Josefinos de Marialdo e ordenado sacerdote em 1956, na Itália. De retorno ao Brasil, trabalhou ao lado do Irmão Cechin junto a movimentos de trabalhadores rurais gaúchos, vindo também a promover e animar dezenas de CEBs pelo interior do Rio Grande do Sul. Faleceu em 2002, aos 73 anos. Os 2 representaram uma forte dupla de pastores em Emaús.

\footnotetext{
${ }^{19}$ Acompanhar trajetória de Luiz Alberto Gomez de Souza em Souza (2015).

${ }^{20}$ Sobre o Irmão Cecchin ver Cechin (2017).
} 
Membros importantes de denominações evangélicas também ajudaram a compor o grupo de Petrópolis. Três nomes devem aqui ser mencionados - Jether Ramalho, Zwinglio Dias e Júlio de Santa Ana.

O primeiro, nascido em 1923, é membro da Igreja Congressional, sociólogo e professor universitário. Nas décadas de 1950 e 1960, teve presença destacada, ao lado de Waldo César, na formação de um campo ecumênico progressista no país. Também foi figura-chave na criação e na manutenção do Centro Ecumênico de Documentação e Investigação (CEDI), uma entidade inspirada em princípios norteadores de uma teologia da libertação de cariz protestante e voltada à defesa da democracia. Jether, na primeira fase do Emaús, teve papel decisivo tanto ao colocar em pauta questões voltadas ao diálogo inter-religioso quanto por participar na fundação e na diretoria de dois braços do Emaús - o CESEEP e o CEBI. (RAMALHO, 2010).

Nascido em 1941, Zwinglio Dias é pastor presbiteriano, doutor em Teologia pela Universidade de Hamburgo e professor de Ciências da Religião da Universidade Federal de Juiz de Fora (UFJF). Formou com Jether em iniciativas de renovação do movimento ecumênico brasileiro, assim como na direção do CEDI. Júlio de Santa Ana é doutor em Teologia protestante pela Universidade de Estrasburgo, na Alemanha. (DIAS, 2018, informação oral). Nascido em 1934 no Uruguai, Santa Ana é leigo metodista e figura de proa no movimento ecumênico internacional, tendo assumido responsabilidades em várias instituições, como a Igreja e Sociedade na América Latina (ISAL), o Conselho Ecumênico das Igrejas (COE) e o Conselho Mundial de Igrejas (CMI). Fixou-se no Brasil em meados da década de 1970, quando veio a participar do Grupo de Petrópolis, da fundação do CESEEP, além de ministrar cursos na Universidade Metodista de São Paulo (UMESP) ${ }^{21}$.

Por fim, cabe registrar a presença de outros dois nomes nessa quadra da história do Emaús - o monge Marcelo Barros e a agente pastoral Maria José Rosado Nunes, a "Zeca" - ambos com forte presença em movimentos populares cristãos no Nordeste, Centro-Oeste e Norte do país. Nascido em 1944, Barros é beneditino e biblista. Em sua trajetória de religioso, esteve ao lado figuras-chave da Teologia da Libertação, tais como

\footnotetext{
${ }^{21}$ Ver verbete de Faustino Teixeira sobre Julio Santa Ana em Cheza, Zaavedra e Sauvage (2017, p. 419-421).
} 
Padre Helder Câmara, Joseph Comblin e Carlos Mesters. Foi coordenador nacional da Comissão Pastoral da Terra (CPT) e, desde 2001, é membro da Comissão Teológica da Associação dos Teólogos do Terceiro Mundo. É membro ativo do Emaús desde a década de 1980. (BARROS, 2013, informação oral).

Maria José Rosado Nunes nasceu em Minas Gerais e lá ingressou como irmã na Ordem da Providência de GAP. Durante a década de 1970, atuou como agente de pastoral junto às CEBS do interior da Bahia e no Acre, estabelecendo contato com vários religiosos e teólogos da Teologia da Libertação. Convidada por João Batista Libanio, em 1979, foi a primeira mulher a fazer parte do Grupo de Petrópolis. Na década seguinte, tornou-se mestra em Ciências Sociais pela PUC-SP e pela Universidade Católica de Louvain e doutora pela École de Hautes Études en Sciences Sociales. É professora na PUC-SP, onde desenvolve programas de pesquisa sobre questões femininas e de gênero e sobre o papel das religiões nas sociedades modernas. Por atestar limites do grupo no campo das discussões relativas à condição feminina, desligou-se do Emaús na década de 1990 (NUNES, 2017, informação oral)

Tendo em vista esse conjunto de dados, passemos a compor um breve perfil da primeira geração dos membros do Grupo de Petrópolis. São critérios classificatórios sexo, faixa etária, nacionalidade, divisão regional, denominação religiosa, formação, carreira profissional e redes de sociabilidade.

1. Temos um total de 18 indivíduos, sendo 17 homens e 1 mulher. A temática da mulher apresentava pouca ressonância na primeira fase da história do grupo. Esse quadro começou a se modificar somente ao longo dos anos 1980, quando a questão feminina ganhou maior centralidade pari passu a uma presença numérica mais significativa de mulheres em Emaús.

2. Até o momento, levantamos dados de idade de 16 membros. Quando se fixa o ano referência em 1974, verifica-se que os primeiros membros do Emaús cobriram uma faixa etária entre 28 e 51 anos, sendo que 8 entre 30 e 39 e 5 entre 40 a 49. Conviveram no grupo 2 gerações, mas a média de idade é de 34 a 35 anos, que pode ser considerada baixa tendo em vista a alta escolaridade. 
3. Dezesseis são brasileiros e apenas dois estrangeiros - 1 holandês e 1 uruguaio. $A$ divisão regional é seguinte: a grande maioria dos membros é oriunda de estados do Sudeste brasileiro - Minas Gerais, Rio de Janeiro e São Paulo. Há 4 oriundos dos estados do Sul - Rio Grande do Sul e Santa Catarina - e apenas 1 do Nordeste - Pernambuco. Essa concentração regional se acentua quando se verifica que 2 membros do Sul - os irmãos Boff - exerceram por muito tempo suas atividades profissionais no sudeste - Rio de Janeiro.

4. Temos 15 católicos e apenas 3 protestantes. Os católicos são oriundos de várias ordens - dominicana, franciscana, jesuíta, carmelita, servos de Maria, marista, josefinos, beneditinos e Ordem da Providência de GAP. José Oscar Beozzo é o único padre diocesano. A ala protestante foi inicialmente composta por um membro da Igreja Congressional e 2 presbiterianos. Em etapas posteriores da história do grupo, essa desproporção foi levemente atenuada, conquanto se mantenha a presença majoritária dos católicos.

5. O grupo de Petrópolis congregou - e ainda congrega - membros das elites religiosas do país, haja vista historicamente reunir um grande número de teólogos e de professores de alta qualificação. Dentre os 18 membros temos 13 doutores, dos quais 7 são teólogos, 5 são cientistas sociais e 1 é historiador. Todos eles realizaram estudos de formação no exterior, em instituições de amplo prestígio, tais como as universidades alemãs em Munique, Hamburgo e Estrasburgo, a Gregoriana, em Roma, a Católica de Louvain ou a École de Hautes Études en Sciences Sociales, em Paris. Exatamente por isso, eles passaram a exercer atividades docentes em seminários e universidades brasileiras. Dos 18 membros acima arrolados, 15 exerceram ou exercem a docência superior. No Brasil, há instituições religiosas que reuniram - ou ainda reúnem - vários membros do Emaús. Três delas merecem destaque: a PUC-Rio, principal celeiro de quadros para o grupo; a PUC-SP e, mais recentemente, a UFJF. 
6. O grupo de Petrópolis, depois Emaús, formou-se na perspectiva de fundamentar, alimentar e dar sentido a uma práxis evangélica transformadora e libertadora. Em razão disso, muitos de seus membros dividiam - e ainda dividem - seu tempo entre o magistério e o trabalho popular contínuo. Esse é um importante traço constituidor e definidor do grupo. Teoria e prática, por questão de princípio, sempre caminham juntas.

7. No desenvolvimento da pesquisa, verificamos que não há como abordar a trajetória do Emaús sem examinar em profundidade as redes que o compõem e as que o grupo ajudou a construir e alimentar. Nesse caso, cremos que a noção "núcleo" ou "vertente" pode ser útil para nos ajudar a trabalhar com esse tema. Quando acompanhamos a dinâmica da formação do grupo, vemos que os 2 pequenos núcleos iniciais - cada qual com sua história própria - fizeram um movimento em 3 direções tendo em vista reforçar o caráter estratégico da articulação, a saber: a) a cientistas sociais católicos que mantinham diálogo aberto com o marxismo e sua aplicação como método de análise social; b) a sacerdotes e agentes de pastoral que mantinham vínculos diretos com as CEBs e outros movimentos sociais; e c) a membros-chave do protestantismo de esquerda no Brasil.

8. O resultado dessa movimentação, ao que os dados apresentam, foi bastante significativo tendo em vista o objetivo de afirmar o posicionamento estratégico do Emaús em redes nacionais e internacionais que compuseram e compõem a Teologia da Libertação. A nova composição do grupo, mais numerosa e abrangente, contribuiu, em primeiro lugar, para reforçar o Emaús como um celeiro de intelectuais/assessores voltados a atuação direta junto às CEBs e junto a outros movimentos de cunho social. Em segundo lugar, favoreceu o estabelecimento de contatos do grupo com entidades e redes internacionais cristãs, entre as quais a formada em torno do CMI, verdadeiro centro de gravidade do protestantismo progressista. Para tal, foi importante contar no grupo com figuras como Jether Ramalho e Júlio de Santa Ana. 
9. Vários membros do grupo se destacaram - e se destacam - na capacidade de ocupar e construir redes e espaços de sociabilidade. Quatro nomes, em particular, merecem registro nesse sentido: João Batista Libanio - fundador e presidente da Sociedade de Teologia e Ciências da Religião (SOTER) no país, tendo sido seu primeiro presidente; Oscar Beozzo - liderança da rede CEHILA no Brasil, fundador e coordenador do CESEEP e nome-chave do grupo em São Paulo; Jether Ramalho - principal referência e ponte de contato com o movimento ecumênico; e Frei Betto - ponta de lança do grupo na articulação das esquerdas cristas e principal interlocutor junto aos movimentos populares.

\section{Palavras finais}

Para concluir, cabe adicionar mais duas perguntas ao nosso roteiro de pesquisa:

1. Qual foi a agenda privilegiada do grupo nesses anos de formação e expansão e quais foram suas principais iniciativas?

2. E o que dizer da ressonância do Emaús para as décadas subsequentes?

O Grupo de Petrópolis, como vimos, foi criado em 1974 - um ano-chave na história da ditadura militar brasileira, a qual já apresentava fissuras e sérios problemas de legitimidade. Prova disso foi a crescente votação da oposição nos pleitos legislativos daquele ano. Para os detentores do poder, era a hora de mudar e de adotar uma "saída pelo alto", ou seja, promover e conduzir um processo de liberalização controlada, que pressupunha certa descompressão político-social. Eram tempos de "distensão lenta, gradual e segura". Para os movimentos populares, por seu turno, era hora de ganhar fôlego e as ruas e retomar a organização em sindicatos e comunidades. Para tal, muitas vezes, passaram a contar com o concurso e com o apoio direto de bispos e padres progressistas da Igreja Católica.

O Emaús, portanto, foi formado nesse quadro e com a missão de dar direção, fundamentação e sustentação às CEBs e aos demais movimentos sociais; essa sempre foi - e provavelmente será - sua principal agenda. 
Quanto às iniciativas, é possível citar 3 delas:

1. A participação articulada de seus membros fundadores na formulação, estruturação e realização de vários encontros nacionais das CEBs, vindo a contribuir para alçar esses movimentos a um novo patamar de organização e mobilização;

2. A liderança de membros do Emaús na formulação, na disseminação e na institucionalização de uma nova metodologia de leitura da Bíblia. Coube ao CEBI ordenar esse campo;

3. A criação de um órgão diretamente voltado à formação evangélica ecumênica e a fazer avançar a educação popular no país - o CESEEP, principal instrumento de disseminação dos valores político-religiosos-civilizacionais defendidos pelo Grupo de Petrópolis, mais tarde Emaús.

E, finalmente, quanto à ressonância do trabalho do Emaús nos campos religioso e político, cabe pensarmos em duas direções. Uma delas consiste em chamar atenção para o papel do grupo em ajudar a compor uma feição própria e original à Teologia da Libertação brasileira, ou seja, para bem além do estrito controle eclesiástico. Outro aspecto é considerar o Emaús como um vetor importante na constituição de um novo “campo popular no país”, dados os vínculos orgânicos de vários de seus membros com um sem-número de movimentos sociais e com o chamado "novo sindicalismo", que então emergiam com vigor na cena política brasileira.

\section{Referências bibliográficas}

BARROS, Marcelo. Entrevista cedida ao autor. Havana (Cuba), 2013.

BETTO, Frei. Batismo de sangue. Rio de Janeiro: Rocco, 2006.

BETTO, Frei. Dilma e o grupo Emaús. 2014a. Disponível em: <http://oglobo.globo.com/ sociedade/dilma-o-grupo-emaus-14732865>. Acesso em: 10 maio 2015.

BETTO, Frei. Entrevista cedida ao autor. Rio de Janeiro, 2012. 
BETTO, Frei. João Batista Libanio (1932-2014). 2014b. Disponível em:

<https://www.brasildefato.com.br/node/27332/>. Acesso em: 7 set. 2018.

BETTO, Frei. Frades dominicanos: 800 anos. 2016. Disponível em:

<https://oglobo.globo.com/sociedade/frades-dominicanos-800-anos-19951798>. Acesso em: 26 set. 2019.

BÍBLIA SAGRADA. Rio de Janeiro: Barsa, Lucas, cap. 24, 13-35, 1964, p. 75-76.

BINGEMER, Maria Clara. Entrevista cedida ao autor. Rio de Janeiro, 2014.

BOFF, Leonardo. Entrevista cedida ao autor. Petrópolis, 2013.

BRITO, Frei Fernando. Cartas do sítio. Editora do Autor: Conde, 2002.

CAVALCANTI, Tereza Maria Pompéia. A leitura popular da Bíblia e a V Conferência do CELAM. Atualidade Teológica, Rio de Janeiro, v. 11, n. 25, p. 76-103, 2007.

CECHIN, Matilde (Org.). Irmão Antônio Cechin: "Seguindo o caminho" (At. 9,2) em busca da Terra Sem Males. Porto Alegre: Marista, 2017.

CHEZA, Maurice; ZAAVEDRA, Luiz Martínez; SAUVAGE, Pierre (Dir.). Dictionnaire historique de la Théologie de la Libération. Numur, Belgique: Lessius, 2017.

DIAS, Zwinglio. Entrevista cedida ao autor. Email, 2018.

DOSSE, François. La marcha de las ideas: historia de los intelectuales, historia intelectual. València, Espanya: Universitat de València, 2007.

FERREIRA, Jorge; REIS, Daniel Aarão (Org.). Revolução e democracia. Rio de Janeiro: Civilização Brasileira, 2007. (Coleção As esquerdas no Brasil, v. 3).

FORTES, Alexandre (Org.). História e perspectiva da esquerda. São Paulo/Chapecó, SC: Perseu Abramo/Argos, 2005.

GOMES, Angela de Castro. Essa gente do Rio... modernismo e nacionalismo. Rio de Janeiro: Ed. FGV, 1999.

GONTIJO, Rebeca. História, cultura e sociabilidade intelectual. In: BICALHO, Maria Fernanda; GOUVÊA, Maria de Fátima Silva (Org.). Culturas políticas: ensaios de história cultural, história política e ensino de história. Rio de Janeiro: Maud/FAPERJ, 2005. p. 259284 . 
INSTITUTO HUMANITAS UNISINOS - IHU. Ver, julgar e agir: 50 anos de prática social católica. 2011. Disponível em: <http://www.ihu.unisinos.br/noticias/43514-ver-julgar-e-agir50-anos-de-pratica-social-catolica>. Acesso em: 26 set. 2019.

JOÃO XXIII. Carta encíclica Mater et Magistra. Disponível em http://w2.vatican.va/content /john-xxiii/pt/encyclicals/documents/hf_j-xxiii_enc_15051961_mater.html. Acesso em: 01/10/2019.

LESBAUPIN, Ivo. Entrevista cedida ao autor. Rio de Janeiro, 2013.

LÖWY, Michael . “As esquerdas na ditadura militar: o cristianismo da libertação”. In: FERREIRA, Jorge; REIS, Daniel Aarão. Revolução e democracia. Rio de Janeiro: Civilização Brasileira, 2007. (Coleção As esquerdas no Brasil, v. 3).

MANFREDI, Silvia Maria. Formação sindical no Brasil: história de uma prática cultural. São Paulo: Escrituras, 1996.

\section{MARQUES, Mariana Pascal. A construção do campo da educação popular no Brasil:} história e repertórios. 210 f. Dissertação (Mestrado em Educação) - Pontifícía Universidade Católica de São Paulo, São Paulo, 2008.

NUNES, Maria José Rosado. Entrevista cedida ao autor. São Paulo, 2017.

OLIVEIRA, Pedro Ribeiro. Entrevista cedida ao autor. Juiz de Fora, 2014.

OLIVEIRA, Pedro Ribeiro. Fé e política: uma trajetória. Juiz de Fora, MG: Quatro Irmãos, 2018.

PONTES, Heloísa. Destinos mistos: os críticos do Grupo Clima em São Paulo (1940-1968). São Paulo: Companhia das Letras, 1998.

RAMALHO, José Ricardo (Org.). Uma presença no tempo: a vida de Jether Ramalho. São Leopoldo, RS: Oikos, 2010.

REIS, Daniel Aarão. Ninguém solta a mão de ninguém. 2018. Disponível em: <https://oglobo.globo.com/opiniao/ninguem-solta-mao-de-ninguem-23334403>. Acesso em: 30 dez. 2018.

SIRINELLI, Jean-François. Le harsard ou la necessité? Une historie en chantier: I'historie des intellectuels. Vingtième Siècle: Revue d'Historie, n. 9, p. 97-108, 1986.

SIRINELLI, Jean-François. Os intelectuais. In: RÉMOND, René (Org.). Por uma história política. Rio de Janeiro, Ed. FGV, 1996. p. 231-269 
SOUZA, Luis Alberto Gomez de. Um andarilho entre duas fidelidades: religião e sociedade. Rio de Janeiro: Ponteio/Universidade Cândido Mendes, 2015.

TREBITSCH, Michel. Avant-propos: la chapelle, le clan et le microcosme. Les cahiers de I'Institut d'Historie Du Temps Present, Paris, n. 20, p. 11-21, 1992.

WILLIAMS, Raymond. Cultura. Rio de Janeiro: Paz e Terra, 1992.

WILLIAMS, Raymond Cultura e materialismo. São Paulo: Ed. Unesp, 1999. 